\title{
Alarm fatigue a top patient safety hazard
}

$\mathrm{M}$ edical device alarms are designed to save lives, but excessive and misleading alerts remain a leading technological hazard in hospitals.

Clinical devices sound hundreds of alarms per patient per day, creating a cacophony that can overwhelm, distract and desensitize health workers, the US Emergency Care Research Institute reveals in its report, 2014 Top 10 Health Technology Hazards.

Caregivers with "alarm fatigue" are more likely to ignore or have trouble distinguishing between alarms, which can lead to delayed treatment and patient harm, the US Food and Drug Administration cites a report indicating there were 566 alarm-related deaths between 2005 and 2008. In the same period, Health Canada received 16 voluntary reports from hospitals of incidents tied to cardiac monitor alarms.

Addressing alarm fatigue is "like opening Pandora's box," says Maria Cvach, the nurse lead of the alarm committee at Johns Hopkins Hospital in Baltimore, Maryland. "There are so many different arms to the problem."

One is the sheer number of bells, beeps and chimes that echo through the modern hospital. A 12-day alarm sys-
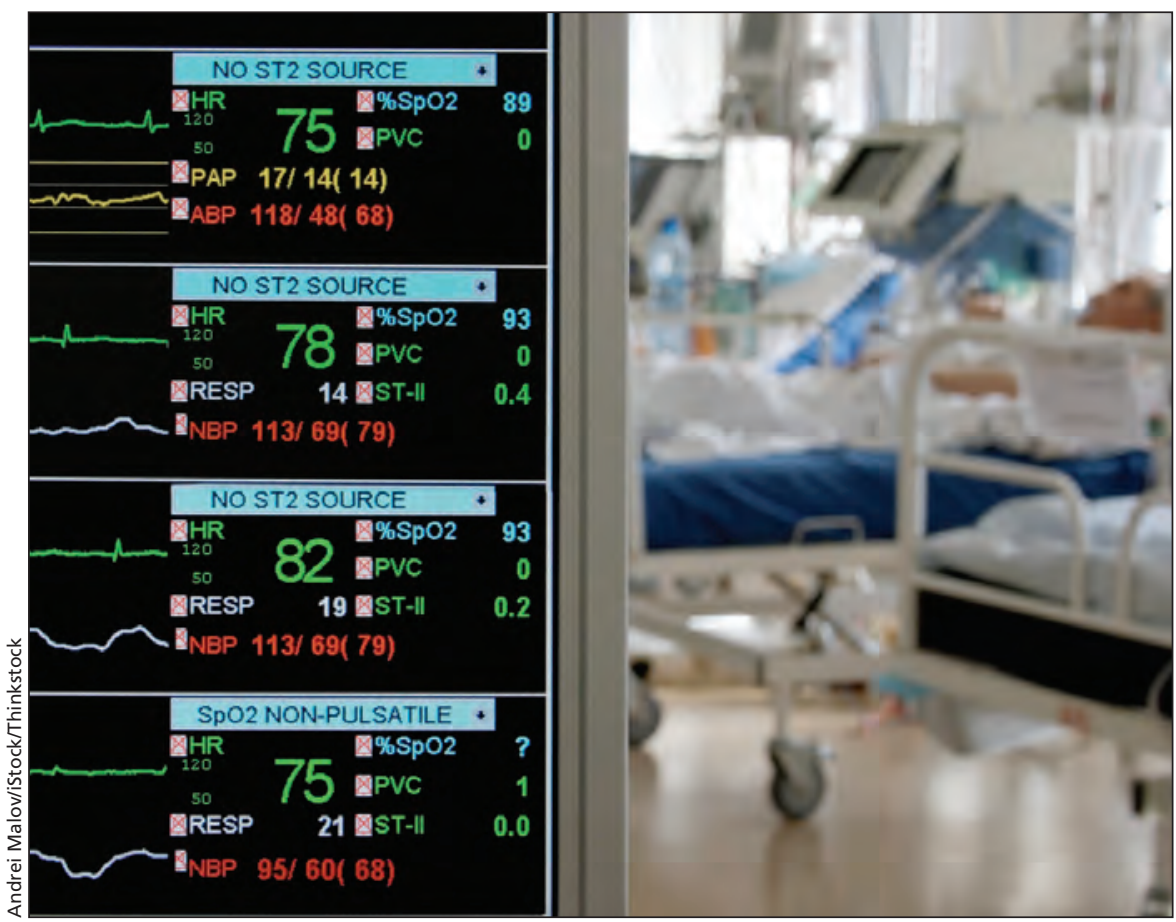

Tens of thousands of alerts may signal throughout a hospital each day, but the majority are false or nuisance alarms.

it difficult for health workers to triage their response to alerts.

In addition, the more often a device issues false alarms, the less likely health workers are to respond. "It's very much the fable of crying wolf,"

\section{The US Food and Drug Administration cites a report indicating there were 566 alarm-related deaths between 2005 and 2008.}

tem analysis at Johns Hopkins indicated there were an average 350 alerts per bed per day. In one intensive care unit, the average was 771 alerts per bed per day.

Tens of thousands of alerts may signal throughout a hospital each day, according to The Joint Commission, the organization that accredits American hospitals. Yet some $85 \%-90 \%$ of these alerts are false or nuisance alarms, indicating conditions that don't require clinical intervention.

Adding to the confusion, there's no standardization of alarm sounds between device manufacturers, making says Judy Edworthy, a professor of applied psychology at Plymouth University in the United Kindgom.

Although there's growing awareness of this problem, there are few efforts to design alarms to be more effective, says Edworthy.

Most initiatives to date have focused on tweaking settings to ensure that a narrower range of conditions prompt alarms. One such initiative at Johns Hopkins saw a $24 \%-74 \%$ reduction in the number of alarms per bed per day across six units.

Edworthy is collaborating with a hospital to develop alarms that are eas- ier to hear, understand and locate. She says the technology exists to create audible, meaningful alarms, but more investment is needed to make these "smart" alerts a reality.

Medical device companies are beginning to heed this call for change, says Sean Clarke, director of the nursing collaborative program at McGill University in Montréal, Quebec. Alarm fatigue experts have presented at recent Canadian Medical and Biological Engineering Society conferences, and Health Canada is meeting with industry representatives to discuss possible solutions.

Clarke says the issue of alarm management will likely take on increasing urgency in coming years, as new technologies are brought to market. Kierra Jones, $C M A J$

CMAJ 2014. DOI:10.1503/cmaj.109-4696

\section{More News online}

To read more CMAJ news articles, visit cmaj.ca/site/home/news.xhtml 